\title{
Failure and Stupidity
}

\author{
James F Welles* \\ East Marion, New York, USA \\ *Corresponding author: James F Welles, East Marion, New York, USA
}

\section{Opinion}

If we have so consistently failed in our efforts to establish a world of peace and plenty for all, it may be because we are not trying to do that. Most people and corporations are basically out for themselves and not much interested in improving the system. Although they may be un- consciously involved in cooperative, synergistic movements to construct more complex societies, this is, at best, half of the story. For ages, people have flattered themselves with the pleasing notion that we are intelligent, God's favorites, free, etc. Recently, analysts have carried on this tradition by emphasizing the anabolic aspects of civilization, and it is true, we can and do cooperate, and the whole can be greater than the sum of the sacrificing parts [1]. However, there is another side to the story, and it is not as flattering as that which emphasizes our constructive nature. It is a legacy of the cynics and their intellectual descendants who viewed humanity as mean, depraved, evil and stupid.

Not surprisingly, scientists have been reluctant to carry on this tradition, and those who have not usually been well received. The shock and dismay that greeted Freud's revelations are representative of the reactions of both the public and professionals to theories about human behavior that are both sound and unsettling. He has been denounced for fabricating evidence, falsifying cures and being generally wrong (especially about women), but he gave meaning to individual lives in a culture of alienation created by Nietzsche [2]. As we all know, the sad fact of life is that there is a catabolic side to nature. Civilizations both rise and fall. The same schemas which promote social cohesion can and it seems invariably do corrupt learning and adaptation and thus lead to their own disintegration. The whole becomes less than the sum of its parts as it dominates to the point of preventing subgroups from carrying out their functions effectively. Although Americans do not brag about it, the United States was peopled by failures. Their ancestors emigrated because they were or anticipated being failures in the old country. Upon arrival, they failed in farming, mining, business and battles. Crackpots invented ships that would sink, shovels that would not dig and boilers that would explode [3]. Builders constructed firetraps that were safe at any height-until they collapsed. As development progressed, slums arose in the cities while in the country, land was cleared so that the topsoil could erode faster. Railroads to nowhere were constructed with promoters then misleading the unwary into settling along the wrong-of-way so that they could be more easily exploited later on. This was due not only to a cog-nitive/intellectual but also a moral failing, with people failing to do what they should, doing instead what they should not-with the term "Should" denoting a fading, ethical imperative [4].

\section{References}

1. Corning P (1983) The Synergism Hypothesis. McGraw-Hill, New York, USA.

2. Watson P (2010) The German Genius. HarperCollins, New York, USA.

3. Hone P (1837) Diary of Philip Hone. In: B Tuckerman (Edt.), New York, USA.

4. Carey A (1990) The United States of Incompetence. Philadelphia Inquirer, New York, USA. 
CC (P) This work is licensed under Creative

To Submit Your Article Click Here: $\quad$ Submit Article

DOI: $10.32474 /$ OAJCAM.2019.01.000130

Open Access Journal of Complementary
\& Alternative Medicine
Assets of Publishing with us
- Global archiving of articles

